B. Indu MD, Y.K. Batra mD mNams, G.D. Puri MD, H. Singh MD MAMS

\title{
Nifedipine attenuates the intraocular pressure response to intubation following succinylcholine
}

Forty patients without eye disease, undergoing elective nonophthalmic surgery, were studied to evaluate the efficacy of sublingual nifedipine in attenuating the intraocular pressure response to succinylcholine administration, laryngoscopy and intubation. The patients were randomly given either nifedipine $10 \mathrm{mg}$ or placebo sublingually 20 minutes before induction of anaesthesia. Intraocular pressure (IOP) and systolic blood pressure (SBP) were recorded before and after induction of anaesthesia. The IOP response to succinylcholine administration, laryngoscopy and intubation was significantly less in patients receiving nifedipine $(P<0.01)$. The mean maximum rise in IOP above basal level at one minute post-intubation was $7.82 \mathrm{mmHg}$ in the control group compared with $0.15 \mathrm{mmHg}$ in the nifedipine pre-treated group. These results suggest that sublingual nifedipine is effective in attenuating the IOP response after succinylcholine administration, laryngoscopy and intubation.

Control of intraocular pressure (IOP) is crucial for open ophthalmic procedures. ' Proper anaesthetic management contributes significantly to a successful surgical outcome. Succinylcholine administration causes a transient but significant increase in IOP, ${ }^{2}$ which is further increased by tracheal intubation. ${ }^{3}$ Various attempts have been made to attenuate the IOP response, but most of these methods have been only partially successful. ${ }^{4-8}$

A sudden increase in blood pressure may cause a

\section{Key words}

EYE: intraocular pressure; PHARMACOLOGY: calcium channel blocker, nifedipine; NEUROMUSCULAR RELAXANTS: succinylcholine.

From the Department of Anesthesiology, Post-graduate Institute of Medical Education and Research, Chandigarh 160012 (India).

Address correspondence to: Dr.Y.K. Batra, Department of Anaesthesiology, P.G.I., Chandigarh - 160012 (India). transient but acute increase in IOP until the aqueous flow dynamics can accommodate. ${ }^{9}$ Nifedipine, a calcium channel blocker, has been found to attenuate the reflex circulatory response to laryngoscopy and intubation. ${ }^{10}$ Thus, the present investigation was planned to study the effects of nifedipine on IOP.

\section{Methods}

Forty patients of either sex, aged 30-40 years, ASA physical status I, without eye disease, scheduled for elective non-ophthalmic surgery were selected for study. They were randomly assigned to control (Group $A, n=$ 20 ) or nifedipine groups (Group $B, n=20$ ) with random number charts. Patients with preexisting elevated IOP (glaucoma), hypertension, obesity, neuromuscular or intracranial diseases were not included in the study. The procedure for measurement of IOP was explained in detail and informed consent obtained. All the patients were premedicated with meperidine $1 \mathrm{mg} \cdot \mathrm{kg}^{-1}$ and promethazine $0.5 \mathrm{mg} \cdot \mathrm{kg}^{-1} \mathrm{IM}$ one hour before induction of anaesthesia. Twenty minutes before the induction of anaesthesia the patients were given either a $10 \mathrm{mg}$ nifedipine gelatine capsule or a placebo capsule of similar physical characteristics sublingually by the third author who was not involved in the rest of the study.

Anaesthesia was induced in all patients with a sleep dose of thiopentone (4-5.5 $\mathrm{mg} \cdot \mathrm{kg}^{-1}$ ) given slowly over a period of 40-50 seconds to obtund the eye lash reflex, followed by succinylcholine $1.5 \mathrm{mg} \cdot \mathrm{kg}^{-1}$. Laryngoscopy was attempted one minute after succinycholine administration and intubation completed within 30 seconds in all the patients. Any patient in whom tracheal intubation proved difficult or who strained or coughed during intubation was excluded from the study. Meanwhile, ventilation was assisted/controlled with a mask, using a Bain anaesthetic breathing circuit delivering 70 per cent nitrous oxide in oxygen at a total fresh gas flow of 100 $\mathrm{ml} \cdot \mathrm{kg}^{-1}$ body weight. ${ }^{11}$

After tracheal intubation, ventilation was controlled with 70 per cent nitrous oxide in oxygen with a Servo 
TABLE Demographic data

\begin{tabular}{llllll}
\hline & Age (year) & Weight $(\mathrm{kg})$ & $\operatorname{Sex}(M / F)$ & IOP $(\mathrm{mmH})$ & $S B P(\mathrm{mmHg})$ \\
\hline $\begin{array}{l}\text { Group A } \\
\mathrm{n}=20\end{array}$ & $34.6 \pm 3.9$ & $64.9 \pm 4.2$ & $12 / 8$ & $18.53 \pm 1.84$ & $121.8 \pm 10.32$ \\
$\begin{array}{l}\text { Group B } \\
\mathrm{n}=20\end{array}$ & $36.3 \pm 3.6$ & $65.9 \pm 5.4$ & $13 / 7$ & $17.48 \pm 1.67$ & $119.4 \pm 11.9$ \\
\hline
\end{tabular}

All values mean $\pm \mathrm{SD}$.

ventilator (Siemens Elema $900 \mathrm{~B}$ ) at a respiratory rate of 12 breaths $\cdot \mathrm{min}^{-1}$ with $\dot{V}$ approximating $110 \mathrm{ml} \cdot \mathrm{kg}^{-1}$. Systolic blood pressure, heart rate and IOP were measured at the following times:

A Before nifedipine pretreatment (control value).

B Twenty minutes after pretreatment, i.e., just before induction of anaesthesia.

C After injection of thiopentone.

D After succinylcholine administration (immediately after fasciculations had ceased).

E,F,G At one, two and three minutes respectively following intubation.

Heart rate and arterial pressure were recorded using an automatic monitor (Nippon Colin Co., Japan), All measurements of IOP were made with a Schiotz tonometer ${ }^{9.12}$ (technique accurate to within $\pm 2 \mathrm{mmHg}$ ) by the first author who was unaware of the nature of the sublingual capsule. Readings were taken in both eyes following topical administration of four per cent lidocaine. The mean of the two readings was recorded. Two-way analysis of variance was used to analyse changes within the groups and unpaired $t$ test for analysis between the groups. $\mathrm{P}<0.05$ was considered to indicate statistical significance. The correlation cofficient was found for SBP and IOP.

\section{Results}

The patients in both the groups were comparable with regard to age, body weight, resting IOP and systolic blood pressure (Table). The change in IOP and SBP in both the groups during the induction sequence are presented in Figure 1 and Figure 2 respectively. There was a significant decrease in IOP after pretreatment with nifedipine in Group B $(P<0.05)$. In both groups IOP decreased after administration of thiopentone. The increase in IOP following succinylcholine administration and tracheal intubation was significantly less in Group $B$ than in Group A $(P<$ 0.01 ). The mean maximum rise in IOP above basal level at one minute post-intubation was $7.82 \mathrm{mmHg}$ in Group $\mathrm{A}$ compared with $0.15 \mathrm{mmHg}$ in the nifedipine pretreated patients in Group B (Figure 1). The maximum increase in IOP at one minute post-intubation in Group A and B patients was $14.80 \mathrm{mmHg}$ and $6.40 \mathrm{mmHg}$ respectively.

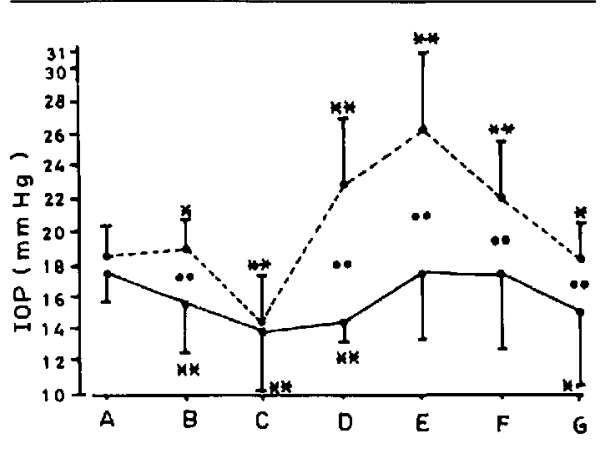

FIGURE 1 Intraocular pressure (IOP) in control (+.--) and nifedipine $(-)$ treated patients at various time intervals. A - before nifedipine pre-treatment (control value). B - twenty minutes after pre-treatment, i.e., just before induction of anaesthesia. C - After injection of thiopentone. D - After succinylcholine administration. E,F and $\mathrm{G}$ - one, two and three minutes after tracheal intubation.

Within group comparison *P $<0.05$, ${ }^{* *} P<0.01$; Between group comparison $" \mathrm{P}<0.05, \cdots \mathrm{P}<0.01$

Only one patient in group $\mathrm{B}$ experienced an increase in IOP greater than $5 \mathrm{mmHg}$. The increase in SBP above the basal level in group B patients one minute after tracheal intubation was $8.55 \mathrm{mmHg}$ compared with $21.7 \mathrm{mmHg}$ in control patients. Although SBP and IOP values at each time interval were not constantly correlated, the combined correlation coefficient between all values of SBP and IOP for Group A as well as Group B showed significant correlation $(r=0.49, P<0.01$ for group $A ; r$ $=0.52, \mathrm{P}<0.01$ for group $\mathrm{B}$ ).

\section{Discussion}

Several studies have demonstrated that succinylcholine administration causes an increase in IOP. To avoid the use of succinylcholine, pancuronium and vecuronium have been used for rapid intubation in patients in whom an increase in IOP is undesirable. ${ }^{13,14}$ However, the search for methods to allow the safe use of succinylcholine in 


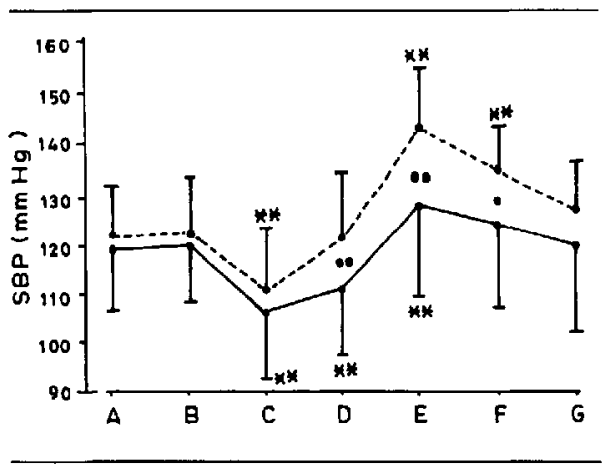

FIGURE 2 Systolic blood pressure (SBP) in control (---) and nifedipine (- treated patients at various time intervals. For symbols see Figure 1 .

patients with penetrating eye injuries continues because succinylcholine remains the drug of choice to provide good conditions for rapid intubation. ${ }^{15,16}$ Pretreatment with a nondepolarizing neuromuscular relaxant, ${ }^{4}$ diazepam $^{5}$ and lidocain ${ }^{8}$ have been suggested to prevent succinylcholine induced increase in IOP, although others have found these measures to be ineffective. ${ }^{6-8,17}$

Nifedipine, a dihydropyridine, is well absorbed by oral or sublingual routes. After a single SL administration of $10 \mathrm{mg}$ nifedipine, an antihypertensive action is obvious at 20-30 min. ${ }^{18,19}$ A significant decrease in IOP was found in nifedipine-pretreated patients before induction of anaesthesia. Nifedipine further prevented the increase in IOP after succinylcholine administration, laryngoscopy and intubation. This effect might be due to obtunded haemodynamic response as SBP in nifedipine-treated patients was significantly less following laryngoscopy and intubation and there was significant correlation between IOP and SBP values of each group. In addition there may be some direct effect of nifedipine on aqueous flow dynamics as IOP decreased below the basal level in patients pretreated with nifedipine without any significant fall in SBP before the induction of anaesthesia.

Other factors such as CVP or $\mathrm{PaCO}_{2}$ could have affected the results. ${ }^{20,21}$ However, we do not expect any change in CVP as all the patients were kept horizontal throughout the period of study. We did not monitor $\mathrm{PaCO}_{2}$, but again we do not expect any significant change in $\mathrm{PaCO}_{2}$ during this short period of study as all the patients were ventilated adequately before and after tracheal intubation with Bain circuit ${ }^{11}$ and Servo ventilator respectively.

In conclusion sublingual nifedipine when employed as pretreatment significantly attenuates the IOP response that follows succinylcholine administration and tracheal intubation in young patients. However, it will be interesting to study the drug in older age groups and in patients with increased IOP coming for surgery.

\section{References}

1 Cunningham AJ, Berry $P$. Intraocular pressure - physiology and implications for anaesthetic management. Can Anaesth Soc J 1986; 33: 195-208.

2 Lincoff $H A$, Ellis $C H$, Devoe $A G$ et al. The effect of succinylcholine on intraocular pressure. Am J Ophthalmol 1955; 40: 501-10.

3 Pandey K, Badola RP, Kumar S. Time course of intraocular hypertension produced by suxamethonium. $\mathrm{Br} J$ Anaesth 1972; 44: 191-6.

4 Miller RD, Way WL, Hickey RF. Inhibition of succinylcholine-induced increased intraocular pressure by nondepolarizing muscle relaxants. Anesthesiology 1968; 29 . 123-6.

5 Cunningham AJ, Albert O, Cameron J, Watson AG. The effect of intravenous diazepam on rise of intraocular pressure following succinylcholine. Can Anaesth Soc J 1981; 28: 591-6.

6 Meyers EF, Krupin T, Johnson M, Zink $H$. Failure of non-depolarizing neuromuscular blockers to inhibit succinylcholine induced increased intraocular pressure, a controlled study. Anesthesiology 1978, 36: 359-65.

7 Feneck RO, Cook JF. Failure of diazepam to prevent the suxamethonium induced rise in intraocular pressure. Anaesthesia 1983; 38: 120-7.

8 Abou-Madi MN, Keszler H, Yacoub JM. Cardiovascular reactions to laryngoscopy and tracheal intubation following small and large intravenous doses of lidocaine. Can Anaesth Soc J 1985; 24: 12-19.

9 Donlon $J V$. Anaesthesia for eye, ear, nose and throat. In: Anaesthesia. Miller RD (Ed.). New York: Churchill Livingstone. 2nd Edition. 1986 pp. 1837-94.

10 Puri GD, Batra YK. Effects of nifedipine on cardiovascular responses to laryngoscopy and intubation. $\mathrm{Br}_{\mathrm{T}} \mathrm{J}$ Anaesth 1988; 60: 579-81.

11 Spoerel WE. Rebreathing and carbon dioxide elemination with the Bain circuit. Can Anaesth Soc J 1980; 27: 357-62.

12 Miller SJH. Parson's diseases of the eye. New York: Churchill Livingstone. 17th Edition. 1984, p. 79.

13 Litwiller RW, Difasio CA, Rushia EL. Pancuronium and intraocular pressure. Anesthesiology 1975; 42: 750-2.

14 Mirakhur RK, Shepherd WFI, Lavery GG, Elliout P. The effect of vecuronium on intraocular pressure. Anaesthesia 1987 ; 42: 944-9.

15 Barr $A M$. Thornley $B A$. Thiopentone and pancuronium crash induction. A comparison with thiopentone and suxamethonium. Anaesthesia 1978; 33: 25-31. 
16 Churchill-Davidson HC (Ed.). A practice of Anzesthesia in Hong Kong. PG Publishing Ptc Ltd 1984. Chapter 25, p. 728.

17 Smith $R B$, Babinski $M$, Leano $N$. The effect of lidocaine on succinylcholine induced rise in intraocular pressure.

Can Anaesth Soc J 1979; 26: 482-3.

18 Guazzi $M$, Olivari MT, Polese A et al. Nifedipine, a new antihypertensive with rapid action. Clin Pharm Therapeutics 1977; 22: 528-32.

19 Beer $N$, Callegos I, Cohen A et al. Efficacy of sublingual nifedipine in acute treatment of systemic hypertension. Chest 1981; 79: 571-4.

20 Hvidberg A, Kessing SV, Fernandes A. Effect of changes in $\mathrm{PCO}_{2}$ and body positions on intraocular pressure during general anaesthesia. Acta Ophthalmologica 1981; 59; 465-9.

21 Smith RB, Aass AA, Nemoto EM. Intraocular and intracranial pressure during respiratory alkalosis and acidosis. Br J Anaesth 1981; 53: 967-71.

\section{Résumé}

Nous avons évalué le rôle de la nifédipine sub-linguale dans la prévention de l'augmentation de la pression intra-oculaire suivant l'injection de succinylcholine et l'intubation chez 40 patients aux yeux normaux. Le hasard déterminait s'ils allaien recevoir $10 \mathrm{mg}$ de nifédipine ou un placebo 20 minutes avam l'induction de leur anesthésie pour chirurgie non-ophtalmique. Nous mesurions les pressions intra-oculaire $(P I O)$ et artérielle systolique (PAS) avant et après cette induction. L'augmentation maximale moyenne de la PIO une minute après l'intubation a été de $7.82 \mathrm{mmHg}$ dans le groupe placebo et de $0.15 \mathrm{mmHg}$ dans le groupe nifedipine $(P<0.01)$. Donc, la nifédipine sublinguale semble capable de limiter l'augmentation de la P1O suivant la séquence succinylcholine-laryngoscopie-intubation trachéale. 